\title{
Tiotropium as an Add-on Treatment Option for Severe Uncontrolled Asthma in Preschool Patients
}

\author{
Stefan Zielen (1) \\ Gianna Reichert' \\ Helena Donath' \\ Jordis Trischler' \\ Johannes Schulze' \\ Olaf Eickmeier' \\ Martin Eckrich ${ }^{2}$ \\ Katharina Blumchen (iD) \\ 'Department for Children and \\ Adolescents, Division of Allergology, \\ Pulmonology and Cystic Fibrosis, \\ University Hospital Frankfurt, Frankfurt, \\ Germany; ${ }^{2}$ Group Practice Dres. Med. \\ Martin Eckrich and Matthias Gründler, \\ Offenbach am Main, Germany
}

This article was published in the following Dove Press journal:

Journal of Asthma and Allergy

Background: Toddlers with asthma suffer disproportionally more than school-aged children from exacerbations with emergency visits and hospital admissions despite inhaled corticosteroid (ICS) treatment. A recent trial for children $\leq 5$ years showed tolerability of tiotropium and potential to reduce asthma-related events.

Methods: We conducted a retrospective analysis of electronic outpatient records (20172019 ) of children $<6$ years treated with ICS plus long-acting $\beta_{2}$-agonists (LABAs) plus tiotropium as an add-on for uncontrolled severe asthma. The primary endpoint was a comparison of systemic corticosteroid (SCS) prescriptions 6 months before and after ICS/LABA/tiotropium start. Secondary endpoints included physician visits, hospitalisations and antibiotic prescriptions. We compared outcomes with children without asthma matched for age, sex, season and screening date.

Results: Compared with a mean $2.42(95 \% \mathrm{CI}: 1.75,3.36)$ SCS courses per patient within 6 months prior to ICS/LABA/tiotropium, 0.74 (95\% CI: 0.25, 1.08) SCS courses per patient were prescribed within 6 months after starting ICS/LABA/tiotropium $(P<0.001)$. Physician visits dropped from 9.23 (95\% CI: 7.15, 12.72) to 5.76 (95\% CI: 3.10, 7.70) per patient $(P<0.01)$. Nineteen hospitalisations were recorded 6 months before ICS/LABA/tiotropium compared with one hospitalisation after $(P<0.01)$. A mean 1.79 antibiotic courses $(95 \% \mathrm{CI}$ : $1.22,2.23)$ per patient were prescribed before ICS/LABA/tiotropium compared with 0.74 (95\% CI: $0.22,1.00)$ after ICS/LABA/tiotropium $(P<0.001)$. Hospitalisation rates for patients at observation end were not statistically different from healthy controls before/ after matching.

Interpretation: Our retrospective study showed that adding tiotropium to ICS/LABA is a new treatment option for patients with severe preschool asthma; however, larger confirmatory studies are needed.

Keywords: preschool asthma, severe uncontrolled asthma, tiotropium, inhaled steroids, long-acting $\beta_{2}$-agonists, LABAs

\section{Introduction}

Asthma is the most common chronic disease in children, imposing a high lifetime burden on individuals, their caregivers and healthcare systems. ${ }^{1}$ Asthma is one of the main causes of hospitalisation in children and is particularly common in those aged $<5$ years. $^{2}$ Young children with asthma have increased vulnerability to adverse outcomes due to smaller airways, and possibly increased bronchial reactivity, in comparison with older children. ${ }^{3}$
Correspondence: Stefan Zielen Department for Children and Adolescents, Division of Allergology, Pulmonology and Cystic Fibrosis, University Hospital Frankfurt, TheodorStern-Kai 7, Frankfurt 60590, Germany $\mathrm{Tel}+49$ (69) 630I-83063

Email Stefan.Zielen@kgu.de
Journal of Asthma and Allergy 2021:14 23-30 
Diagnosing asthma in preschool children is challenging due to the heterogeneity of the disease, the continuing development of the immune system in a young population and the lack of diagnostic options such as lung function measurements. $^{4,5}$ Recurrent wheezing occurs in a large proportion of preschool children, typically with viral respiratory tract infections, but deciding when this is the initial presentation of asthma is often difficult for healthcare professionals. ${ }^{5,6}$

Validated treatment options are scarce due to the paucity of data overall and lack of conclusive studies in such a young patient population. The Global Initiative for Asthma (GINA) recommends treatment with daily lowdose inhaled corticosteroids (ICS) for preschool children with persistent asthma. ${ }^{7}$ If symptoms do not improve or become worse, increasing the dose of ICS or adding additional treatment with leukotriene receptor antagonists (LTRAs) is recommended. ${ }^{6,8,9}$ However, ICS therapy in preschool children with persistent asthma has its limitations: whilst a recent meta-analysis found strong evidence to support daily ICS use, with a reduction in exacerbations of $44 \%$, total prevention of exacerbations was not achieved. ${ }^{10}$ Continuous use of ICS in children is associated with side effects including growth retardation; keeping the ICS dose low considerably reduces side effects. ${ }^{11}$ At present, there are insufficient data for guidelines to recommend additional controller therapies, such as combinations of ICS with long-acting $\beta_{2}$-agonists (LABAs) or long-acting muscarinic antagonists (LAMAs) in this age group. ${ }^{7}$

Tiotropium is the only registered and recommended LAMA add-on therapy for use in children $>6$ years and adults. ${ }^{12-14}$ Our group recently showed that inhalation of tiotropium using a soft mist inhaler is suitable for children aged $<5$ years, although children aged $<5$ years needed assistance from a parent/caregiver and/or a valve holding chamber. ${ }^{15,16}$ Safety and tolerability of tiotropium have been shown to be similar to those of placebo, and improvements in lung function have been shown across various age groups and asthma severities. ${ }^{12-14,17} \mathrm{~A}$ recent study in young children (aged 1-5 years) with persistent asthmatic symptoms found that tiotropium added to ICS with and without additional controller medicine was well tolerated and showed potential to reduce the risk of asthma exacerbations compared with placebo. ${ }^{17}$

Since our centre was strongly engaged in the development programme of tiotropium, we were optimistic that adding a LAMA to ICS might be of great value for children with uncontrolled preschool asthma. Additionally, Frankfurt serves as one of the four major asthma clinics in Germany. We get referral of many patients with uncontrolled preschool asthma. Taking our early experience with LAMA into account, we started to use tiotropium more liberally, in severe cases, outside a controlled study although tiotropium is still not licensed in children below 6 years in Europe.

The aim of this retrospective, real-life pilot study was to evaluate therapeutic outcomes including number of hospitalisations, severe exacerbations with systemic corticosteroid (SCS) demand, number of physician visits and number of antibiotic prescriptions, 6 months before and 6 months after the start of therapy with ICS/LABA/LAMA in children aged $<6$ years with severe preschool asthma. The results are compared with healthy children matched for age, sex and screening date.

\section{Methods}

We carried out a retrospective analysis of the electronic medical records (Medistar CompuGroup Medical SE \& Co. KGaA, Hannover, Germany) of our paediatric and adolescent outpatient clinic for allergic and respiratory diseases at the University Hospital in Frankfurt, Germany from 2017 to 2019 to identify children who had commenced ICS/LABA/tiotropium therapy.

Before starting treatment with tiotropium, a detailed verbal and written explanation took place about the possible benefits and side effects of tiotropium as well as the off-label use. Prior to retrospective data collection, written informed consent was obtained from all caregivers. Additionally, caregivers consented to us contacting the local physician to get all external data transferred to our clinic and to have these data published. Ethics approval was obtained from the ethics committee of Goethe University in Frankfurt (application number 149/19). The study was conducted in accordance with the Declaration of Helsinki.

The diagnostic criteria and treatment algorithm in these patients were completely similar and based on current GINA guidelines, starting with ICS and if patients were still uncontrolled adding a second preventer like montelukast, LABA or both treatment options. Tiotropium as an add-on treatment to ICS/LABA was recommended by the paediatric pneumology staff after discussing each single case with severe uncontrolled asthma in detail. In addition, we contacted the local physicians/paediatricians of these children and asked them to send us a print-out of their electronic charts 6 months before and 6 months after starting ICS/LABA/ 
tiotropium therapy to document all consultations and antibiotic prescriptions in this two-part observation period.

To be included in the study, patients had to be diagnosed with uncontrolled severe asthma (as defined by Pedersen et $\mathrm{al}^{18}$ ); in addition, patients had $\geq 1$ asthma exacerbation within 6 months prior to screening and had to be aged between $>6$ months and $<6$ years at the time of the first ICS/LABA/tiotropium dose. Children suffering from an additional genetic disease such as cystic fibrosis, other significant lung diseases or immunodeficiencies were excluded. The primary endpoint was the number of SCS treatments in the group of children with severe uncontrolled asthma after 6 months of ICS/LABA/tiotropium treatment compared with the 6 months before treatment. Secondary endpoints included the number of physician visits (local paediatrician), hospital stays and antibiotic prescriptions. Since the numbers of physician visits and antibiotic prescriptions in this age group were not known, these outcomes were compared to a healthy control group. We also evaluated treatment success (as estimated by parents or caregivers) using a 10 -point Likert scale, with a rating of 10 suggesting very good improvement and a rating of 0 meaning no improvement at all. Healthcare utilisation, including visits to the local paediatrician, prescriptions of antibiotics and rate of hospitalisations, was compared pre and post ICS/LABA/ tiotropium treatment within the group of children with asthma as well as compared to the healthy control group.

\section{Statistical Analysis}

Basic descriptive statistics including absolute and relative frequency distributions and two-sided 95\% confidence intervals (CIs) are reported. Statistical analyses were performed with GraphPad Prism 5.0 (GraphPad Software, San Diego, CA, USA). For comparisons, the MannWhitney $U$-test or the Wilcoxon-Mann-Whitney test and Fisher test were used. $P<0.05$ is statistically significant.

Healthy controls were matched by sex, time interval of observation and age; ie, if a patient with asthma received their first dose of ICS/LABA/tiotropium in December, a control child with the same age, sex and time interval (6 months pre and 6 months after the selection date) was selected by the data bank of the local physician. If no control was available with the exact birthday, a control with the least difference in age was selected. This allowed us to seasonally match the controls to patients (Figure 1). We included this control group since no data on physician visits or antibiotic prescriptions in this age group were available in Germany. All healthy age- and sex-matched

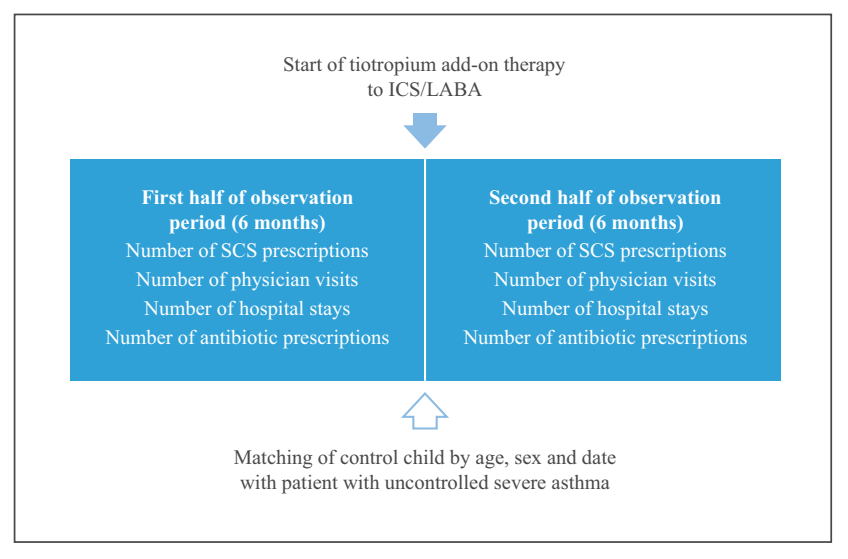

Figure I Design of the retrospective study.

Abbreviations: ICS, inhaled corticosteroids; LABA, long-acting $\beta_{2}$-agonists; SCS, systemic corticosteroids.

controls were recruited by a local general paediatrician. All patient and control subject data were anonymised.

\section{Results}

In 2017-2019, 2184 patients aged 0-18 years were treated in our outpatient clinic. Of these, 934 (42.7\%) were aged $<6$ years; of these, 436 were diagnosed with preschool asthma. Twenty-one patients in this group (4.8\%) received ICS/LABA/tiotropium therapy due to uncontrolled severe asthma. For 19 of these 21 patients, we were able to collect data on SCS prescriptions, hospitalisations and antibiotic prescriptions from their local paediatricians for the 6 months before and after start of their ICS/LABA/ tiotropium therapy. Missing data are either due to unwillingness of the paediatrician to share the electronic charts or due to a frequent change of physicians, meaning that we could not follow up the medical history of the child. Data for the children in the control group are complete. Baseline characteristics of the 21 children with severe uncontrolled asthma treated with ICS/LABA/tiotropium are summarised in Table 1 . In addition to these 21 patients with uncontrolled severe asthma, baseline data for 42 age- and sex-matched controls are also presented. Within the uncontrolled severe asthma group, the median duration of asthma was 23 months; $42 \%$ had received at least ICS/ LABA, and 58\% had received ICS, LABA and LTRA. The mean daily dose of fluticasone was $200 \mu \mathrm{g}$. More than half of the patients with asthma had a family history of atopy; in the control group, patients with a family history of atopy and with atopic dermatitis were excluded. Six patients had a positive prick test $\geq 3 \mathrm{~mm}$. One was monosensitised to mites, one was positive to mites and grass 
Table I Patient and Control Demographics Before Switching to ICS/LABA/Tiotropium Treatment

\begin{tabular}{|c|c|c|c|}
\hline $\begin{array}{l}\text { Demographic Data } 6 \text { Months } \\
\text { Before ICS/LABA/LAMA } \\
\text { Treatment }\end{array}$ & $\begin{array}{l}\text { ICS/LABA/ } \\
\text { LAMA } \\
(n=21)\end{array}$ & $\begin{array}{l}\text { Controls } \\
(n=42)\end{array}$ & $P$ \\
\hline Age, months (range) & $21.7(6-46)$ & $21.7(6-46)$ & \\
\hline Sex (male/female), $\mathrm{n}$ & $11 / 10$ & $22 / 20$ & \\
\hline Family history of atopy, $\mathrm{n}(\%)$ & II (52.4) & 0 & $<0.001$ \\
\hline Atopic dermatitis, n (\%) & $6(28.6)$ & 0 & $<0.001$ \\
\hline Allergy (prick $\geq 3 \mathrm{~mm}$ ), $\mathrm{n}(\%)$ & $6(28.6)$ & 0 & $<0.001$ \\
\hline Passive smoke exposure & $2(9.5)$ & NA & \\
\hline $\begin{array}{l}\text { Duration of asthma, months, } \\
\text { median (range) }\end{array}$ & $23(4-46)$ & NA & \\
\hline ICS/LABA, \% & 42 & NA & \\
\hline ICS/LABA/LTRA, \% & 58 & NA & \\
\hline $\begin{array}{l}\text { Fluticasone, } \mu \mathrm{g} \text {, median daily dose } \\
\text { (range) }\end{array}$ & $\begin{array}{l}200 \\
(100-200)\end{array}$ & NA & \\
\hline $\begin{array}{l}\text { Duration of ICS therapy, months, } \\
\text { median (range) }\end{array}$ & $22(5-44)$ & NA & \\
\hline
\end{tabular}

Note: For comparison the Fisher test was applied.

Abbreviations: ICS, inhaled corticosteroid; LABA, long-acting $\beta_{2}$-agonist; LAMA, long-acting muscarinic receptor antagonist; LTRA, leukotriene receptor antagonist; NA, not applicable.

pollen, and one was positive to mites and birch pollen. In total, mite sensitisation was most common. One was sensitised to birch pollen only, one to ash pollen only, and one to cat and horse. Clinical symptoms suggestive of gastroesophageal reflux disease (GERD) like chronic cough or heartburn were found in eight of 22 patients. Of these eight patients, seven patients underwent combined bronchoscopy and gastroscopy with $\mathrm{pH}$-monitoring for 24 hours. One patient underwent $\mathrm{pH}$-monitoring for 24 hours only. In three of eight patients, GERD was diagnosed and treated.

SCS administration was determined in 19 patients with uncontrolled severe asthma. SCS was given for severe asthma exacerbations when persistent airflow obstruction existed despite bronchodilator treatment. An average of 2.42 SCS courses $(95 \%$ CI: $1.75,3.36)$ per patient were prescribed in the 6 months before starting ICS/LABA/ tiotropium (a total of 46 SCS courses in the whole group). Eight patients were treated parenterally with prednisolone, 28 patients received betamethasone per os for 3 days and 10 patients were treated once with $100 \mathrm{mg}$ prednisolone rectally. In the 6 months after starting ICS/ LABA/tiotropium therapy, the mean number of courses per patient was 0.74 ( $95 \%$ CI: $0.25,1.08$; $P<0.001$ compared with children with asthma in the 6 months before starting ICS/LABA/tiotropium; a total of 14 courses of SCS). In the healthy control group, two of 42 children received two courses of SCS due to severe croup syndrome, each in the first half of the observation period (6 months prior to matching; an average of 0.10 number of courses; 95\% CI: $-0.04,0.23$; four prescriptions in total; $P<0.001$ compared with children with asthma in the 6 months before and after start of ICS/LABA/tiotropium), with no prescription at the end of the second half of the observation period (6 months after matching; $P<0.001$ versus children with asthma in the 6 months after starting ICS/LABA/tiotropium; Figure 2A).

In the 6 months prior to ICS/LABA/tiotropium therapy, 17 patients visited their paediatrician 157 times, with an average of 9.24 visits per patient (95\% CI: $7.15,12.72)$. After 6 months of ICS/LABA/tiotropium, there were 98 visits (average 5.76 per patient; 95\% CI: 3.10, 7.70; $P<0.01$ vs the patients 6 months prior to ICS/LABA/tiotropium therapy). In the control group, there was an average of 3.76 paediatrician visits 6 months prior to matching (95\% CI: $2.87,4.65 ; P<0.01$ vs children with asthma 6 months before start of ICS/LABA/tiotropium; Figure 2B) and 2.60 (95\% CI: $2.04,3.15)$ at the end of the observation period ( $P<0.01$ vs children with asthma 6 months after switch to ICS/LABA/tiotropium and $P<0.05$ vs control children 6 months prior to matching).

In the asthma patient cohort, 19 hospital stays were recorded 6 months before starting ICS/LABA/tiotropium (one hospital stay per patient; 95\% CI: $0.41,1.60$ ), compared with only one hospitalisation 6 months after starting ICS/LABA/tiotropium therapy (average of 0.05 hospital stays per patient; $95 \% \mathrm{CI}:-0.06,0.17 ; P<0.01)$. None of the healthy controls was hospitalised (Figure 2C).

A mean 1.80 (95\% CI: 1.22, 2.23) antibiotic prescriptions for respiratory tract infections per patient in the asthma group were recorded in the 6 months before starting ICS/LABA/tiotropium (34 courses in total), compared with a mean $0.74(95 \%$ CI: $0.22,1.00)$ prescriptions per patient in the 6 months after treatment with ICS/ LABA/tiotropium started $(P<0.01 \quad$ vs patients with asthma in the 6 months before treatment). In the healthy control group, an average of 0.07 (95\% CI: $-0.01,0.15$ ) prescriptions per child were recorded 6 months prior to matching $(P<0.01$ vs children with asthma in the 6 months before starting ICS/LABA/tiotropium therapy) compared with an average of $0.12(95 \% \mathrm{CI}: 0 ; 0.24)$ prescriptions per child at the end of the observation period (five prescriptions in total; $P<0.01$ vs children with asthma in the 6 months after starting ICS/LABA/ tiotropium; Figure 2D). No statistically significant 
A

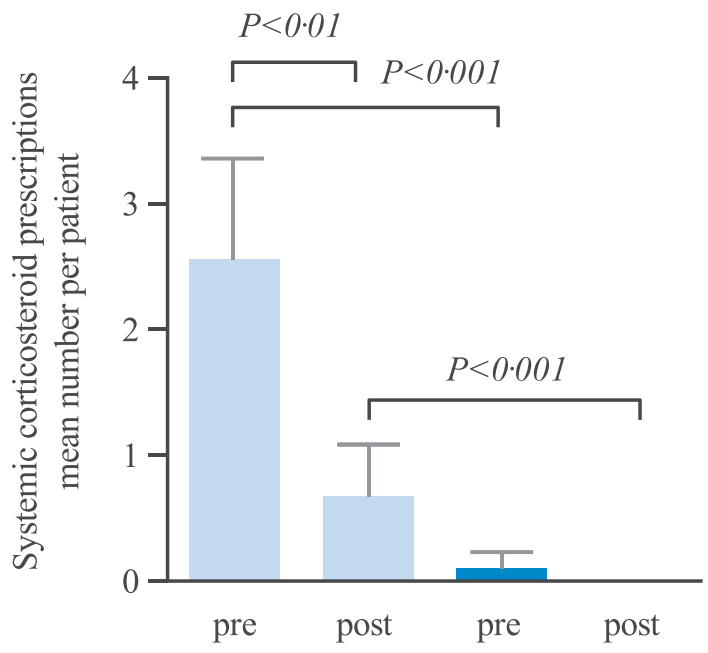

C

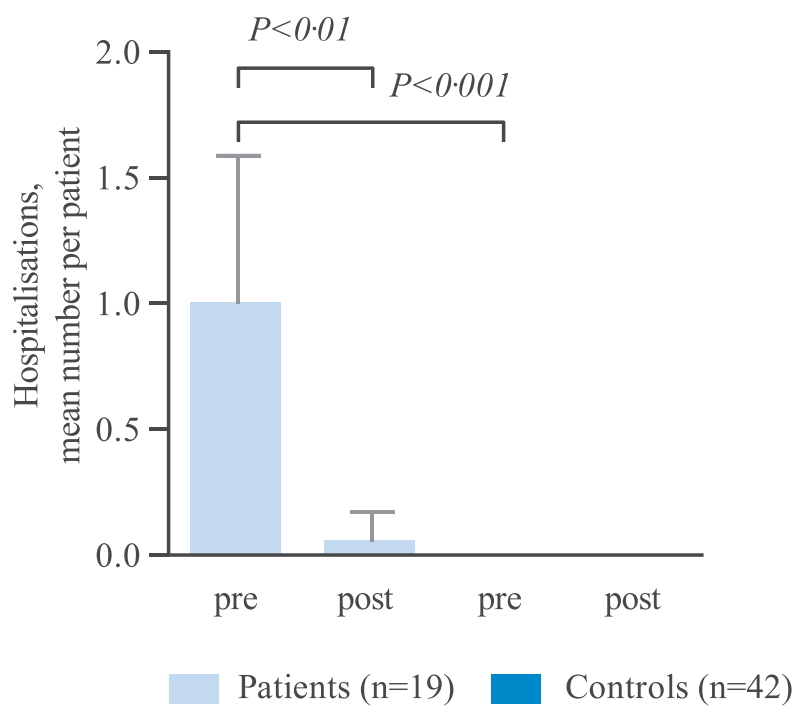

B

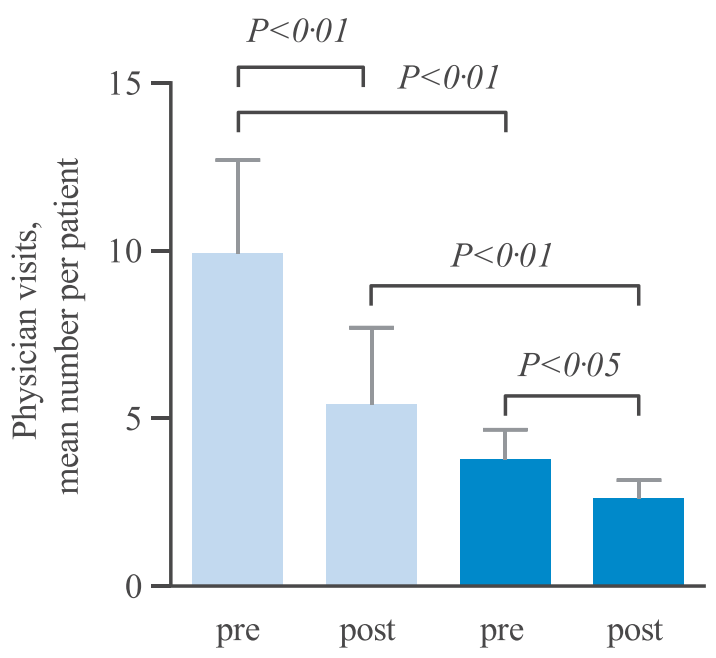

D

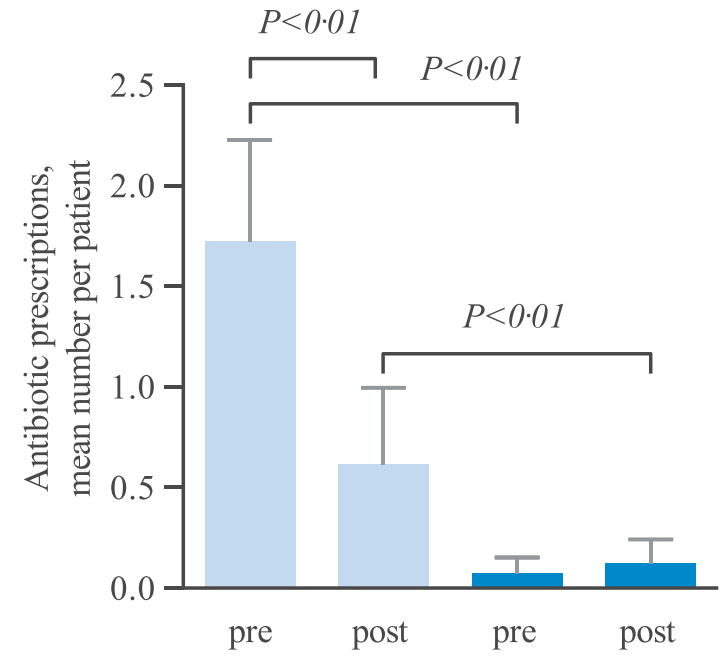

Figure 2 (A) Systemic corticosteroid administration; (B) physician visits; (C) hospitalisations; (D) use of antibiotics. Data are shown as mean \pm standard error of mean. Pre=observation period I (up to 6 months before start of ICS/LABA/tiotropium therapy); post=observation period 2 (up to 6 months after start of ICS/LABA/tiotropium therapy). Treatment differences of tiotropium, physician visits and antibiotic use between pre and post observation were evaluated by the Wilcoxon-Mann-Whitney test. Abbreviations: ICS, inhaled corticosteroids; LABA, long-acting $\beta_{2}$-agonist.

differences in treatment responses were observed with and without LTRA use, either before or after the addition of tiotropium (Table 2).

In terms of perception of treatment success, according to the Likert scale $(0=$ no improvement to $10=$ very good improvement), as estimated by the parents and caregivers of 20 patients with severe asthma, 18 gave scores between 8 and 10; the maximum rating of 10 was given for 12 patients, indicating excellent improvement. For only two patients, a rating of $\leq 4$ was given. The average score was 8.3 ; the median score was 10 (Figure 3 ). Tolerability of tiotropium was excellent. No adverse events were reported.

\section{Discussion}

Optimising asthma management among preschool children is an unmet need, since this age group suffers from significant morbidity, including higher rates of hospitalisation and intensive care unit admission. ${ }^{1,2}$ Tiotropium Respimat ${ }^{\circledR}$ was found to be a well-tolerated and efficacious add-on to ICS plus one or more controller medications in several clinical trials in children and adolescents. ${ }^{12-14,17}$ In addition, a recent trial in preschool children with persistent asthmatic symptoms showed that tiotropium added to ICS was well tolerated and had a potential to reduce the risk of asthma-related events compared with placebo, defined as: a) asthma exacerbation 
Table 2 Treatment Response in Patients with and without LTRA Use

\begin{tabular}{|c|c|c|c|c|c|c|}
\hline & \multicolumn{3}{|l|}{ Before Tiotropium } & \multicolumn{3}{|l|}{ Plus Tiotropium } \\
\hline & \multirow{2}{*}{$\begin{array}{l}\text { ICS without LTRA } \\
(n=9)\end{array}$} & \multirow{2}{*}{$\begin{array}{l}\text { ICS with LTRA } \\
(n=12)\end{array}$} & \multirow[t]{2}{*}{$P$} & ICS without LTRA & ICS with LTRA & \multirow[t]{2}{*}{$P$} \\
\hline & & & & $(n=9)$ & $(n=12)$ & \\
\hline Systemic steroids & $n=13$ & $n=33$ & 0.275 & $n=4$ & $n=10$ & 0.630 \\
\hline Mean & 1.86 & 2.75 & & 0.57 & 0.83 & \\
\hline No data & 2 & 0 & & 2 & 0 & \\
\hline Hospitalisation & $n=3$ & $n=16$ & 0.100 & $\mathrm{n}=0$ & $\mathrm{n}=\mathrm{I}$ & 0.461 \\
\hline Mean & 0.43 & 1.33 & & 0 & 0.08 & \\
\hline No data & 2 & 0 & & 2 & 0 & \\
\hline Antibiotic use & $n=13$ & $n=21$ & 0.834 & $n=6$ & $\mathrm{n}=8$ & 0.680 \\
\hline Mean & 1.86 & 1.75 & & 0.857 & 0.67 & \\
\hline No data & 2 & 0 & & 2 & 0 & \\
\hline Physician visits & $n=68$ & $n=89$ & 0.758 & $n=44$ & $\mathrm{n}=54$ & 0.672 \\
\hline Mean & 9.71 & 8.90 & & 6.29 & 5.4 & \\
\hline No data & 2 & 2 & & 2 & 2 & \\
\hline
\end{tabular}

Notes: Absolute numbers of events ( $n$ ) and average values (event/number of patients) are shown. For comparison the Wilcoxon test was applied.

Abbreviations: ICS, inhaled corticosteroids; LTRA, leukotriene receptor antagonist.

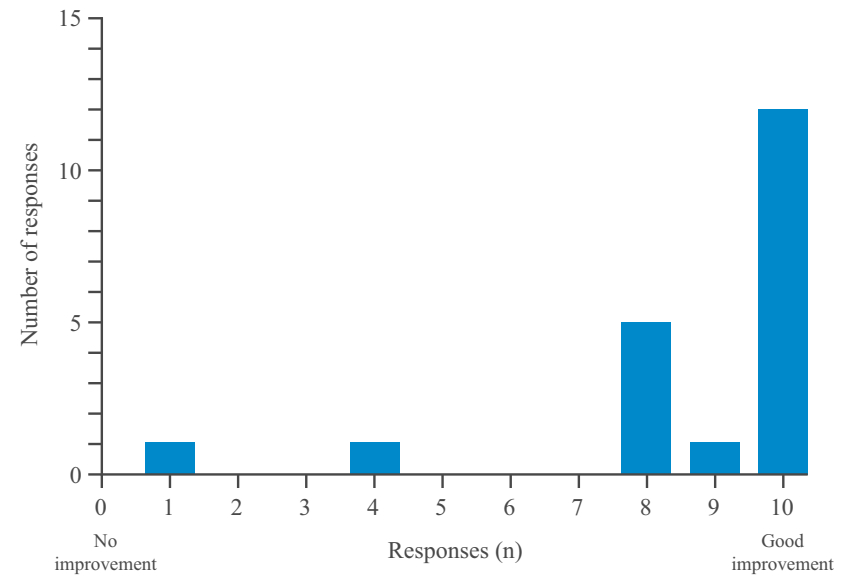

Figure 3 Parental assessment of treatment according to the Likert scale $(0=$ no improvement; $10=$ very good improvement; children with asthma only).

or asthma worsening; b) asthma exacerbations (broad) and asthma worsening; or c) asthma exacerbations (broad) plus pneumonia or asthma worsening. ${ }^{17}$ However, there are currently no reliable data available on the frequency of hospitalisations, SCS courses, physician visits and antibiotic treatments in preschool patients with severe asthma receiving ICS/LABA/tiotropium therapy.

In our retrospective study we observed significant improvements in all measured parameters after 6 months of ICS/LABA/tiotropium treatment. Most impressively, SCS courses dropped from 46 to 14 significantly during observation. The high number of SCS courses before adding tiotropium underpins the severity of our study group. However, it is well known that SCS should be used very restrictively since recent concern has been raised about oral corticosteroid overuse. ${ }^{19,20}$ In addition, asthma control was much increased since hospitalisations and physician visits after ICS/LABA/tiotropium therapy were not statistically different from healthy controls. Moreover, we found that most parents and carers of the asthma group were satisfied with ICS/LABA/tiotropium therapy given to their children.

There is, however, a need for second-line controller medication in young children with asthma who are not well controlled by ICS. ${ }^{6}$ Lemanske et al found that LABA step-up in children aged 6-17 years with uncontrolled asthma was significantly more likely to provide the best treatment response compared with ICS or LTRA step-up. ${ }^{21}$ In addition, optimising asthma management among preschool children by quintupling the dose of ICS at the early signs of loss of asthma control did not reduce the rate of severe asthma exacerbations and may be associated with diminished linear growth. ${ }^{22}$ These findings shaped our hospital's policy to prescribe LABAs, leading to high use in preschool patients with severe asthma. However, more recent data suggest that adding a LABA to ICS in children was not associated with a significant reduction in exacerbations requiring systemic steroids. ${ }^{23,24}$ Thus, adding tiotropium as a second controller in patients with severe 
uncontrolled preschool asthma seems to be much more promising than adding a LABA. In our study, ICS/LABA/ LAMA treatment significantly reduced hospital stays in preschool children with asthma and had a marked socioeconomic impact in terms of direct costs (physician and emergency room visits and hospitalisations) and indirect costs (absence from work of caregivers).

Some reports indicate higher use of antibiotics in asthmatic than in non-asthmatic children; ${ }^{25-27}$ however, antibiotics are not indicated as treatment for asthma exacerbations. Still, many physicians do use antibiotics during exacerbations in real life. Misuse of antibiotics increases microbial resistance, ${ }^{27}$ leading to higher medical costs, prolonged hospital stays and increased mortality. ${ }^{27}$ In our study, ICS/ LABA/LAMA treatment significantly reduced antibiotic use in preschool children with asthma, most likely due to better asthma control.

Our study has several limitations; these include the fact that it was a retrospective analysis and not a randomised clinical trial. Another limitation of the study might be that the controls were healthy, and it would have been better to pair the study population with controls with severe asthma not on tiotropium therapy. However, we were unable to find a fitting control group. Therefore, we decided to compare the study population to healthy controls in order to demonstrate that the need for physician visits and antibiotic prescriptions decreases and nearly approaches "a normal level". In addition, the number of patients included was small, and the data for hospitalisations, antibiotic and SCS prescriptions were available for 19 of the 21 patients. The endpoints for this study were exploratory and used for descriptive statistical analyses only. In addition, the use of a Likert scale instead of a more standardised survey such as the Asthma Control Test further limits our findings.

In conclusion, we have shown that tiotropium is a potential add-on treatment option for preschool patients with severe asthma; however, this population is not currently included in the tiotropium label. ${ }^{12-14,17}$ A two-arm, prospective, double-blind study (ICS plus placebo vs ICS/ LAMA) over 12 months in preschool patients with severe asthma may help to strengthen the evidence to adapt current guidelines to modern care reality.

\section{Acknowledgements}

The corresponding author confirms that he had full access to all the data in the study and had final responsibility for the decision to submit for publication. Medical writing support, furnished by Kristina Standeven, $\mathrm{PhD}$ of
MediTechMedia, was funded by Boehringer Ingelheim. No further funding was received.

\section{Author Contributions}

All authors made substantial contributions to conception and design, acquisition of data, or analysis and interpretation of data; took part in drafting the article or revising it critically for important intellectual content; agreed to submit to the current journal; gave final approval of the version to be published; and agree to be accountable for all aspects of the work.

\section{Disclosure}

SZ reports grants from Goethe University during the conduct of the study and reports grants and personal fees from Bene-Arzneimittel $\mathrm{GmbH}$, grants from ALK Arzneimittel and personal fees from Novartis $\mathrm{GmbH}$, Boehringer Ingelheim, Lofarma GmbH, IMS HEALTH GmbH \& Co. OHG, GSK, Stallergen, Procter and Gamble, Allergopharma $\mathrm{GmbH}$, AstraZeneca, Sanofi/Pasteur and Aimmune outside the submitted work. KB reports non-financial support from Boehringer Ingelheim for medical writing for this manuscript and reports grants, personal fees from Aimmune Therapeutics and research support from DBV technologies, and provided lectures for Bencard Allergie, HAL Allergy, Allergopharma and ALK, outside the submitted work. The authors report no other conflicts of interest in this work.

\section{References}

1. Ferrante G, La Grutta S. The burden of pediatric asthma. Front Pediatr. 2018;6:186. doi:10.3389/fped.2018.00186

2. Akinbami LJ, Moorman JE, Garbe PL, Sondik EJ. Status of childhood asthma in the United States, 1980-2007. Pediatrics. 2009;123:S131S145. doi: $10.1542 /$ peds.2008-2233C

3. Hogg JC, Pare PD, Hackett TL. The contribution of small airway obstruction to the pathogenesis of chronic obstructive pulmonary disease. Physiol Rev. 2017;97(2):529-552. doi:10.1152/physrev.00025.2015

4. Carlsen KH. What distinguishes the asthmatic amongst the infant wheezers? Pediatr Allergy Immunol. 1997;8:40-45.

5. Kurukulaaratchy RJ, Matthews S, Holgate ST, Arshad SH. Predicting persistent disease among children who wheeze during early life. Eur Respir J. 2003;22(5):767-771. doi:10.1183/09031936.03.00005903

6. Beigelman A, Bacharier LB. Management of preschool recurrent wheezing and asthma: a phenotype-based approach. Curr Opin Allergy Clin Immunol. 2017;17(2):131-138. doi:10.1097/ACI.0000000000000344

7. Global Initiative for Asthma. Global strategy for asthma management and prevention (2019 report). Available from: https://ginasthma.org/ wp-content/uploads/2019/06/GINA-2019-main-report-June-2019wms.pdf. Accessed October 29, 2019.

8. Bisgaard H, Zielen S, Garcia-Garcia ML, et al. Montelukast reduces asthma exacerbations in 2- to 5-year-old children with intermittent asthma. $\mathrm{Am}$ J Respir Crit Care Med. 2005;171(4):315-322. doi:10.1164/rccm.200407$8940 \mathrm{C}$

9. Zielen S, Christmann M, Kloska M, et al. Predicting short term response to anti-inflammatory therapy in young children with asthma. Curr Med Res Opin. 2010;26(2):483-492. doi:10.1185/03007990903485148 
10. Kaiser SV, Huynh T, Bacharier LB, et al. Preventing exacerbations in preschoolers with recurrent wheeze: a meta-analysis. Pediatrics. 2016;137(6):e20154496. doi:10.1542/peds.2015-4496

11. Loke YK, Blanco P, Thavarajah M, Wilson AM, Zhang L. Impact of inhaled corticosteroids on growth in children with asthma: systematic review and meta-analysis. PLoS One. 2015;10(7):e0133428. doi:10.1371/journal.pone.0133428

12. Hamelmann E, Bateman ED, Vogelberg C, et al. Tiotropium add-on therapy in adolescents with moderate asthma: a 1-year randomized controlled trial. J Allergy Clin Immunol. 2016;138(2):441-450.e448. doi:10.1016/j.jaci.2016.01.011

13. Paggiaro P, Halpin DM, Buhl R, et al. The effect of tiotropium in symptomatic asthma despite low- to medium-dose inhaled corticosteroids: a randomized controlled trial. J Allergy Clin Immunol Pract. 2016;4(1):104-113.e102. doi:10.1016/j.jaip.2015.08.017

14. Vogelberg C, Szefler SJ, Vrijlandt EJLE, et al. Tiotropium add-on therapy is safe and reduces seasonal worsening in paediatric asthma patients. Eur Respir J. 2019;53(6):pii: 1801824. doi:10.1183/ 13993003.01824-2018

15. Bickmann D, Kamin W, Sharma A, Wachtel H, Moroni-Zentgraf P, Zielen S. In vitro determination of Respimat ${ }^{\circledR}$ dose delivery in children: an evaluation based on inhalation flow profiles and mouththroat models. J Aerosol Med Pulm Drug Deliv. 2016;29:76-85. doi:10.1089/jamp.2014.1166

16. Kamin W, Frank M, Kattenbeck S, Moroni-Zentgraf P, Wachtel H, Zielen S. A handling study to assess use of the Respimat ${ }^{\circledR}$ Soft Mist Inhaler in children under 5 years old. J Aerosol Med Pulm Drug Deliv. 2015;28(5):372-381. doi:10.1089/jamp.2014.1159

17. Vrijlandt EJLE, El Azzi G, Vandewalker M, et al. Safety and efficacy of tiotropium in children aged 1-5 years with persistent asthmatic symptoms: a randomised, double-blind, placebo-controlled trial. Lancet Respir Med. 2018;6(2):127-137. doi:10.1016/S22132600(18)30012-2

18. Pedersen SE, Hurd SS, Lemanske RF, et al. Global strategy for the diagnosis and management of asthma in children 5 years and younger. Pediatr Pulmonol. 2011;46(1):1-17. doi:10.1002/ppul. 21321
19. Farber HJ, Silveira EA, Vicere DR, Kothari VD, Giardino AP. Oral corticosteroid prescribing for children with asthma in a Medicaid managed care program. Pediatrics. 2017;139(5):e20164146. doi:10.1542/peds.2016-4146

20. Matsumoto H, Ishihara K, Hasegawa T, Umeda B, Niimi A, Hino M. Effects of inhaled corticosteroid and short courses of oral corticosteroids on bone mineral density in asthmatic patients: a 4-year longitudinal study. Chest. 2001;120(5):1468-1473. doi:10.1378/ chest.120.5.1468

21. Lemanske RF, Mauger DT, Sorkness CA, et al. Step-up therapy for children with uncontrolled asthma receiving inhaled corticosteroids. $N$ Engl J Med. 2010;362(11):975-985. doi:10.1056/NEJMoa1001278

22. Jackson DJ, Bacharier LB, Mauger DT, et al. Quintupling inhaled glucocorticoids to prevent childhood asthma exacerbations. $N$ Engl J Med. 2018;378(10):891-901. doi:10.1056/NEJMoa1710988

23. Chauhan BF, Chartrand C, Ni Chroinin M, Milan SJ, Ducharme FM. Addition of long-acting beta2-agonists to inhaled corticosteroids for chronic asthma in children. Cochrane Database Syst Rev. 2015;(11): CD007949. doi:10.1002/14651858.CD007949.pub2

24. Yoshihara S, Tsubaki T, Ikeda M, et al. The efficacy and safety of fluticasone/salmeterol compared to fluticasone in children younger than four years of age. Pediatr Allergy Immunol. 2019;30 (2):195-203. doi:10.1111/pai.13010

25. Stallworth LE, Fick DM, Ownby DR, Waller JL. Antibiotic use in children who have asthma: results of retrospective database analysis. J Manag Care Pharm. 2005;11(8):657-662. doi:10.18553/ jmcp.2005.11.8.657

26. De Boeck K, Vermeulen F, Meyts I, Hutsebaut L, Franckaert D, Proesmans M. Coprescription of antibiotics and asthma drugs in children. Pediatrics. 2011;127(6):1022-1026. doi:10.1542/ peds.2009-3068

27. Baan EJ, Janssens HM, Kerckaert T, et al. Antibiotic use in children with asthma: cohort study in UK and Dutch primary care databases. BMJ Open. 2018;8(11):e022979. doi:10.1136/bmjopen-2018-022979

\section{Publish your work in this journal}

The Journal of Asthma and Allergy is an international, peer-reviewed open-access journal publishing original research, reports, editorials and commentaries on the following topics: Asthma; Pulmonary physiology; Asthma related clinical health; Clinical immunology and the immunological basis of disease; Pharmacological interventions and new therapies. The manuscript management system is completely online and includes a very quick and fair peer-review system, which is all easy to use. Visit http://www.dovepress.com/testimonials.php to read real quotes from published authors. 